\title{
Horizontal Cooperation in Logistics: Opportunities and Impediments
}

\author{
Frans Cruijssen $^{\text {a,b }}$, Martine Cools ${ }^{\mathrm{c}}$ ， Wout Dullaert ${ }^{\mathrm{d}}$, Hein Fleuren $^{\mathrm{a}}$ \\ ${ }^{a}$ Tilburg University, Faculty of Economics and Business Administration, Tilburg \\ ${ }^{\mathrm{b}}$ TNO Inro, Logistics and Transportation, Delft \\ ${ }^{c}$ University of Antwerp, Department of Accounting and Finance \\ ${ }^{\mathrm{d}}$ University of Antwerp, Institute of Transport and Maritime Management Antwerp
}

\begin{abstract}
This paper presents the results of a large-scale survey on the potential benefits of and impediments for horizontal collaboration in Flanders. When appropriate, a distinction is made between different types of Logistics Service Providers (LSPs) and between respondents that are currently cooperating on either core or non-core activities, and respondents that are not. The main findings are that in general LSPs strongly believe in the potential benefits of horizontal cooperation to increase their profitability or to improve the quality of their services. The impediments for cooperation that are perceived or expected by the non-cooperating LSPs prove to be experienced by the cooperating LSPs. The estimation of potential cost savings, the measurement and allocation of savings are considered to be the most severe impediments for cooperation. Removing these impediments offers interesting directions for further research.
\end{abstract}

Keywords: Horizontal cooperation; Logistics networks; Freight transportation; Empirical research

JEL code: $\mathrm{C} 40$

Acknowledgement: This research was partially funded by the Flemish Institute for Logistics, www.vil.be. This support is gratefully acknowledged.

\section{Introduction}

Fierce competition in global markets, the introduction of products with shorter life cycles, and the heightened expectations of customers have forced shippers and Logistics Service Providers (LSPs) to invest in developing stronger and mutually beneficial relationships. Such vertical collaboration, involving suppliers, manufacturers, distribution centers, customers and LSPs, is supported by extensive academic research. As indicated by 
Gibson et al. (2002), research has mainly focused on identifying potential benefits (e.g. Gentry, 1993), the critical success factors (e.g. Tate, 1996) and partner selection criteria (e.g. Bradley, 1994). The most common and best-studied type of vertical cooperation involves shippers hiring third party logistics providers to perform all or part of a firm's materials management and product distribution function (Simchi-Levi et al., 2000). For more information on third party logistics, see e.g. Bolumole (2003), Bowman (1995), Davis (1995), Harrington (1996), Leahy et al. (1995) and Tyan et al. (2003).

Except for a small number of successful cases in North America (e.g. Land 'O Lakes), horizontal collaboration in logistics is mainly gaining momentum in Western Europe. In Belgium and the Netherlands, the European logistic centers of gravity, the authors are aware of over 30 formal logistic partnerships. Through close collaboration the partnering LSPs aim at increasing productivity, e.g. by optimizing vehicle capacity utilization, reducing empty mileage and cutting costs of non-core/supporting activities to increase the competitiveness of logistic networks.

The literature on horizontal partnerships in logistics however, is still in its infancy. With the exceptions of maritime shipping (see e.g. Sheppard and Seidman, 2001) and the airline industry (Fan et al., 2001 and Oum et al. 2002), where horizontal collaboration is quite common and well studied, the literature on horizontal logistic partnerships is scarce. To the best of our knowledge, this matter has only been studied by Bahrami (2003), Cruijssen and Salomon (2004), Erdmann (1999), and Vos et al. (2003). In these publications, the emphasis is on (1) quantifying the potential cost savings through cooperation by means of simulation techniques and on (2) reporting a limited number of successful cases.

This paper aims at providing empirical evidence on the potential benefits of horizontal collaboration in logistics, as well as at identifying the major impediments for starting and maintaining logistic partnerships in practice. To the best of our knowledge, a similar large-scale empirical study has not yet been undertaken. The remainder of the paper is structured as follows. In Section 2 research questions are formulated for surveying a large sample of logistics service providers in Flanders, the main logistics region in Belgium. The survey is discussed in Section 3. Sections 4 and 5 respectively report on the opportunities of and the impediments for logistic cooperation. Avenues for further research are identified in Section 6.

\section{Research questions}

In order to gain insight in the attitude of LSPs towards horizontal collaboration with other LSPs, a carefully selected sample of LSPs was asked to evaluate a set of propositions. As Table 1 and Table 2 below indicate, the first subset of propositions focuses on the opportunities of horizontal cooperation, while the second refers to the potential impediments for horizontal cooperation. Because the current status of a logistics service 
provider company (either cooperator or non-cooperator) can color its opinion on logistic collaboration, a distinction is made between cooperating and non-cooperating logistics service providers.

Previous research suggests that horizontal cooperation can increase the productivity of core and non-core activities (Esper and Williams, 2003; Ritter and Gemünden, 2003; Smith et al., 1995). Proposition 1 in Table 1 focuses on productivity gains for core activities (e.g. decrease in empty hauling and a higher utilization rate for storage facilities). Proposition 2 refers to cost savings for non-core activities (e.g. organizing safety training and setting up joint fuel facilities). Collaboration on non-core activities offers the potential of joint purchases (e.g. of vehicles, onboard computers and fuel) in order to reduce the purchasing costs (see proposition 3). This was suggested by Dyer and Singh (1998) to be an important reason for companies to engage in a horizontal partnership. The following propositions in Table 1 consider whether horizontal collaboration allows LSPs to specialize, while offering the same or a wider set of services to customers (proposition 4), and whether horizontal collaboration allows LSPs to tender for larger contracts than before (proposition 5). Proposition 6 focuses on whether LSPs can improve the service level (in terms of speed, frequency of deliveries, geographical coverage, reliability of delivery times etc.) at lower costs and proposition 7 suggests that partnerships could help LSPs to protect their market share/customer base.

Table 1

Propositions about opportunities of horizontal cooperation

\begin{tabular}{ll}
\hline No. & Proposition \\
\hline 1 & $\begin{array}{l}\text { Horizontal cooperation increases the company's productivity for core activities, e.g.: decrease in } \\
\text { empty hauling, better usage of storage facilities etc. }\end{array}$ \\
2 & $\begin{array}{l}\text { Horizontal cooperation reduces the costs of non-core activities, e.g.: organizing safety trainings, } \\
\text { joint fuel facilities etc. }\end{array}$ \\
3 & $\begin{array}{l}\text { Partnerships reduce purchasing costs, e.g.: vehicles, onboard computers, fuel etc. } \\
4\end{array}$ \\
5 & LSPs can specialize, while at the same time broadening their services. \\
6 & Tendering on larger contracts with large shippers becomes possible. \\
7 & Forming partnerships helps to protect market share.
\end{tabular}

Both practice and literature suggest a number of impediments for cooperation, which are summarized in Table 2. Proposition 1 states the difficulty to find suitable candidates for collaboration. Proposition 2 expresses the difficulty in finding a reliable coordinator for the partnership. Proposition 3 addresses the potential loss of identity due to collaboration. The following three propositions deal with the estimation/determination of the benefits (proposition 4), a fair division of the workload (proposition 5), and a fair division of the benefits amongst the partners (proposition 6). Proposition 7 states that smaller partners run the risk of losing customers to the larger partners in the partnership. Proposition 8 suggests that cooperation is hampered by ICT requirements. Finally, proposition 9 expresses the fear that benefits cannot be divided in a fair way, in the sense that the larger players have more power and can thus benefit more. 
Table 2

Propositions about impediments for horizontal cooperation

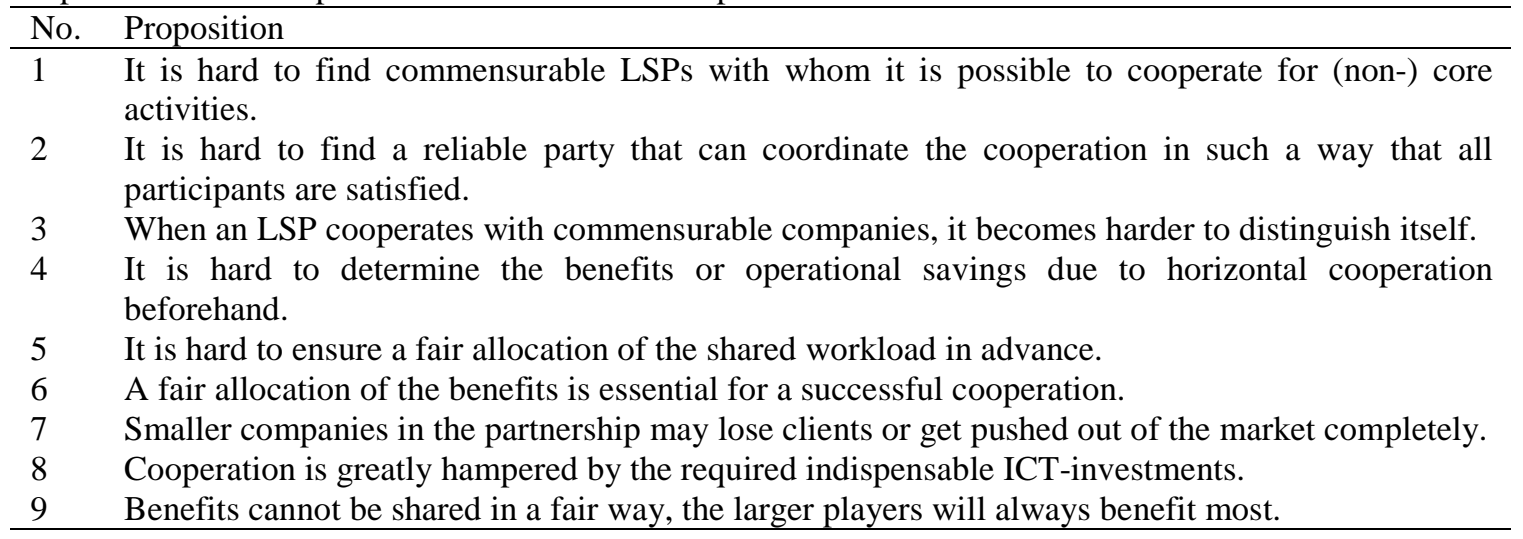

\section{The survey}

The 16 propositions on horizontal collaboration were submitted to a sample of LSPs. Respondents were asked to evaluate each proposition by choosing one of the following options: (1) strongly agree, (2) agree, (3) neutral, (4) disagree, (5) strongly disagree. Section 3 provides detailed information on the composition of the sample, the questionnaire, and the in-depth interviews that were conducted to complement the survey. Moreover, to facilitate the analysis of opportunities and impediments for horizontal cooperation in Section 4, we provide a classification of the respondents.

\subsection{Questionnaire and interviews}

After fine-tuning the questionnaire by means of five pilot interviews, a personalized questionnaire was sent to 1537 Flemish LSPs. The survey was sent out in March 12th 2004, and filled-in questionnaires came in between March 19th and April 14th 2004. In total, 154 useful answers were returned. Eleven in-depth interviews were conducted to crosscheck and fine-tune the findings from the analysis.

\subsection{Sample selection}

The BelFirst database (BelFirst, 2004), containing the annual reports of 250.000 companies in Belgium, was used to construct a representative sample of around 1.500 LSPs. The sample included LSPs with the following Nace-Bel main activity codes: Freight transportation by road (60242), Inland water transportation (612), Cargo handling and storage (631), Freight forwarding (6412) and Courier activities other than national post activities (63401). In the remainder of this paper, we will refer to the latter category as "express carriers". 
With the exception of small companies, Belgian companies are obliged to publish their annual reports. Large companies have to prepare their reports according to the 'complete scheme', while the medium sized companies are allowed to prepare their reports based on a 'contracted scheme'. Our sample was based on the annual reports of 2002, the most recent year for which all reports were deposited. Table 3 provides an overview of the characteristics of the LSPs in the BelFirst database in 2002.

Table 3

Characteristics of the LSPs in the BelFirst database in 2002

\begin{tabular}{lrr}
\hline Characteristic & Complete scheme & Contracted scheme \\
\hline Number of companies & 653 & 4.253 \\
Aggregate turnover (million EURO) & 8.391 & 1.283 \\
Aggregate asset value (million EURO) & 6.032 & 2.977 \\
Aggregate gross product (million EURO) & 2.159 & 1.373 \\
Aggregate number of employees (full time equivalents) & 28.667 & 20.509 \\
\hline
\end{tabular}

The sample size was pre-set to approximately 1.500. Assigning the 1.500 questionnaires to companies with complete or contracted schemes on the basis of turnover, asset value, gross product or the employed staff, would ignore the large number of small companies active in the industry. Instead of using formal weighting factors, $25 \%$ of the questionnaires were sent to companies having to submit a complete annual report and 75 $\%$ to companies sending in a contracted version. This ensures a sufficient representation of the larger companies in view of their economic importance and at the same time offers the possibility to thoroughly survey medium-sized LSPs. To limit the risk of a zero response rate in the smallest categories, questionnaires were sent to all companies in a category with no more than ten companies. In this way, 1537 LSPs were selected: 390 of the larger ones and 1147 small and medium-sized. The distinction between companies with complete or contracted annual reports was used only for the sample selection. In this paper, the distinction will not be used in the analysis of the results.

Table 4 summarizes the structure of the sample. For each cell in the table, the first number refers to the number of companies contained in the sample, the second to the number of LSPs in the BelFirst database.

Table 4

Sample composition according to Nace-Bel main activity codes and the number of employees in full time equivalents

\begin{tabular}{lcccccc}
\hline & \multicolumn{7}{c}{ Number of employees in full time equivalents } \\
Nace-Bel main activity & $0-4$ & $5-19$ & $20-49$ & $50-99$ & $100+$ & \\
\hline Freight transportation by road & $607(2258)$ & $261(888)$ & $132(374)$ & $40(79)$ & $21(37)$ & $1061(3636)$ \\
Inland water transportation & $40(126)$ & $9(10)$ & $3(3)$ & $0(0)$ & $0(0)$ & $52(139)$ \\
Cargo handling and storage & $92(286)$ & $55(142)$ & $29(51)$ & $15(25)$ & $12(19)$ & $203(523)$ \\
Freight forwarding & $58(187)$ & $33(92)$ & $27(44)$ & $14(15)$ & $10(12)$ & $142(350)$ \\
Express carriers & $61(232)$ & $10(18)$ & $6(6)$ & $0(0)$ & $2(2)$ & $79(258)$ \\
\hline
\end{tabular}




\subsection{Characteristics of the respondents}

In this section the 154 respondents are classified based on (1) the number of employees and their Nace-Bel main activity code, and (2) an alternative classification to support the analysis of the survey results in the Sections 4 and 5.

\subsubsection{Number of employees / Nace-Bel main activity codes}

Because only large companies (i.e. companies with a complete scheme) in Belgium are obliged to report the number of employees, BelFirst (2004) provides an estimate of the number of employees for the medium-sized companies (contracted scheme). This estimate, based on the company's turnover and the average turnover per employee for companies with the same Nace-Bel code, was used for the composition of the sample in Table 4. As these estimates could not be retrieved for individual companies, Table 5 is constructed using the number of employees (in full time equivalents) reported in the questionnaires. In columns 2 to 6 , the first number refers to the number of surveys received, the second to the number of companies in the sample. Cases in which the number of employees was not reported are listed in column 7 of Table 5 ('unknown'). Cases in which questionnaires were returned because the address was unknown, or because the company stopped its activities, are reported in columns 8 and 9. These respondents were removed from the sample to calculate the net response rates presented in Table 5. We note that the true response rates may be somewhat higher because not all companies that ceased to exist are expected to return the questionnaire.

Table 5

Net response rate

\begin{tabular}{|c|c|c|c|c|c|c|c|c|c|}
\hline Nace-Bel main activity & \multicolumn{6}{|c|}{ Number of employees in full time equivalents } & $\begin{array}{c}\text { Unknown } \\
\text { address }\end{array}$ & \multirow{2}{*}{ Stopped } & \multirow{2}{*}{$\begin{array}{c}\begin{array}{c}\text { Net } \\
\text { response }\end{array} \\
0.11\end{array}$} \\
\hline Freight transportation by road & $40(606)$ & $31(261$ & $22(132)$ & $8(4)$ & $9(21)$ & 8 & 16 & & \\
\hline Inland water transportation & $2(40)$ & $4(9)$ & $0(3)$ & $0(0)$ & $0(0)$ & 0 & 1 & 0 & 0.12 \\
\hline Cargo handling and storage & $2(92)$ & $5(55)$ & $3(29)$ & $1(15)$ & $3(12)$ & 1 & 3 & 0 & 0.07 \\
\hline Freight forwarding & $2(58)$ & $2(34)$ & $1(27)$ & $1(14)$ & $1(10)$ & 0 & 4 & 3 & 0.05 \\
\hline Express carriers & $3(61)$ & $4(10)$ & $0(6)$ & $0(0)$ & $0(2)$ & 1 & 2 & 0 & 0.10 \\
\hline
\end{tabular}

The net response rate is the highest for companies that are mainly active in road haulage, inland navigation and courier services. The small number of respondents for the activities Inland water transportation (6 respondents) and express carriers (8 respondents) limits the representativeness of the results for those categories. The low response from the Freight forwarders could be due to a low interest in horizontal cooperation. In-depth interviews revealed that these LSPs prefer vertical collaboration in logistics. Horizontal logistic collaboration, e.g. consisting of exchanging loads, could be perceived as a threat to existing professional forwarding activities. The response rate for the LSPs in the category Cargo handling and storage is higher than the response rate for the freight forwarders, but is still quite low (7\%). 


\subsubsection{Logistics Service Provider classification}

Classifying LSPs based on their main Nace-Bel activity codes ignores the fact that many LSPs offer various services and that the shares of each of the activities in the companies' turnover can differ strongly. In order to construct an alternative classification, respondents were asked to estimate the share of each of the following activities in their turnover:

- Road transport

- Rail services

- Inland shipping and short sea shipping

- Forwarding and coordination

- Value Added Services, such as storage, administration and conservation of goods, kitting, reconditioning of goods, labelling, ICT services etc.

Based on the respondents' estimates of the turnover shares, a classification of six groups of LSPs was constructed (see Table 6).

Table 6

Alternative categorization of the respondents

\begin{tabular}{|c|c|}
\hline Category & Description \\
\hline 1 & $\begin{array}{l}\text { Category } 1 \text { is the largest category of respondents and it consists of the pure road } \\
\text { transportation companies. This means that they generate their complete revenue from road } \\
\text { transportation. }\end{array}$ \\
\hline 2 & $\begin{array}{l}\text { The second category consists of companies that generate more than } 50 \% \text { of their total } \\
\text { revenues from modalities other than road transportation. This group of respondents offers } \\
\text { e.g. rail transportation, inland shipping or short sea shipping. }\end{array}$ \\
\hline 3 & $\begin{array}{l}\text { Freight forwarders and road transportation companies that commission a large part of their } \\
\text { orders to subcontractors are classified in category } 3 \text {. These respondents generate } 50 \% \text { or } \\
\text { more of their revenues from these activities. Another requirement is that the respondents do } \\
\text { not offer any Value Added Services. }\end{array}$ \\
\hline 4 & $\begin{array}{l}\text { The respondents in category } 4 \text { offer Value Added Services. However, these are not the core } \\
\text { activities of the LSPs in category 4: the Value Added Services constitute less than } 50 \% \text { of } \\
\text { their total revenue. }\end{array}$ \\
\hline 5 & $\begin{array}{l}\text { Category } 5 \text { consists of LSPs that have Value Added Services as their core activities. These } \\
\text { services make up } 50 \% \text { or more of total revenue for the respondents in category } 5 \text {. }\end{array}$ \\
\hline 6 & $\begin{array}{l}\text { LSPs that are registered in the Nace-Bel database (see Section 3.3.1) as an express carrier } \\
\text { are classified in category } 6 \text {. }\end{array}$ \\
\hline
\end{tabular}

To prevent LSPs from being allocated to several categories, the following priority rule was used: Category $6 \rightarrow$ Category $1 \rightarrow$ Category $2 \rightarrow$ Category $3 \rightarrow$ Category $4 \rightarrow$ Category 5. Once an LSP qualifies for a category, it cannot be allocated to any of the subsequent categories.

An overview of the respondents in terms of the six LSP categories is displayed in Figure 1. More than half of the respondents are pure trucking companies. The number of respondents in categories 2 (8 respondents) and 6 (7 respondents) is low, limiting the representativeness of the analysis of these categories in Sections 4 and 5. 
Figure 1

Allocation of the respondents to the categories

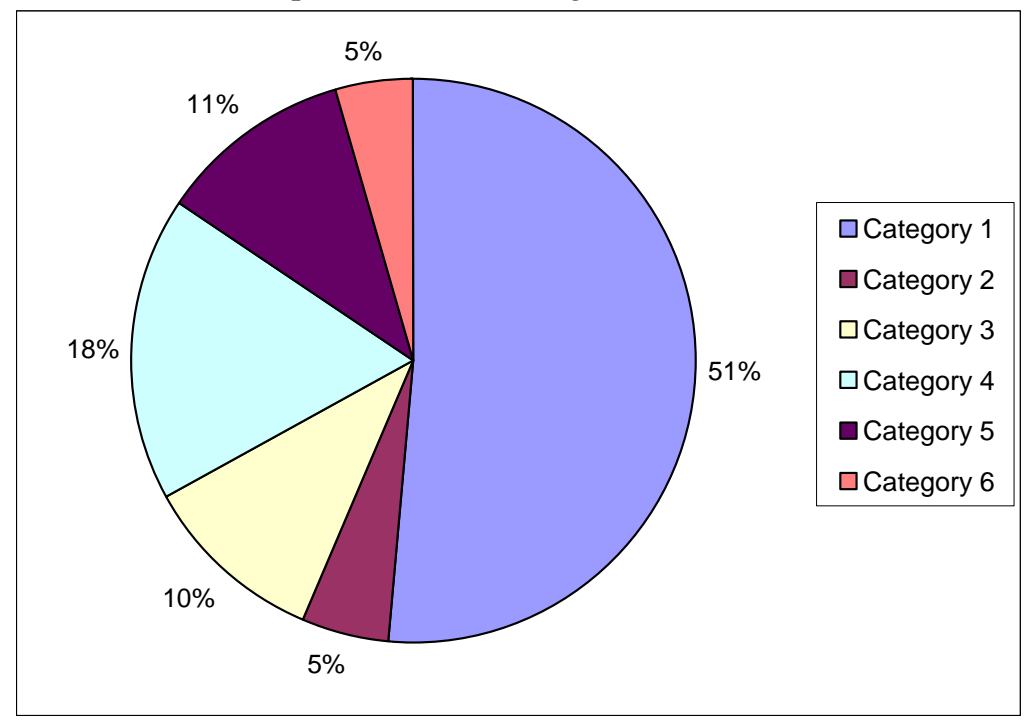

\section{Opportunities of horizontal cooperation}

This section presents the evaluation of the propositions on the opportunities offered by horizontal cooperation, listed in Table 1 of Section 2. First, the evaluation of the entire set of propositions by all respondents is discussed. As some respondents did not evaluate each proposition, the total number of evaluations per proposition differs. Second, the most striking propositions are discussed in detail for the six categories of LSPs (see Section 3.3.2).

Figure 2 suggests that the propositions on the potential benefits of horizontal cooperation are well supported by the respondents. For each proposition, less than $21 \%$ of the respondents disagree. On the other hand, only $49 \%$ of the respondents (74 out of 147) indicate to be interested in (intensified) cooperation in the near future. This score is based on the respondents' evaluation of the following proposition: "In the current situation, you are interested in cooperation with commensurable companies". 
Figure 2

Opportunities of horizontal cooperation

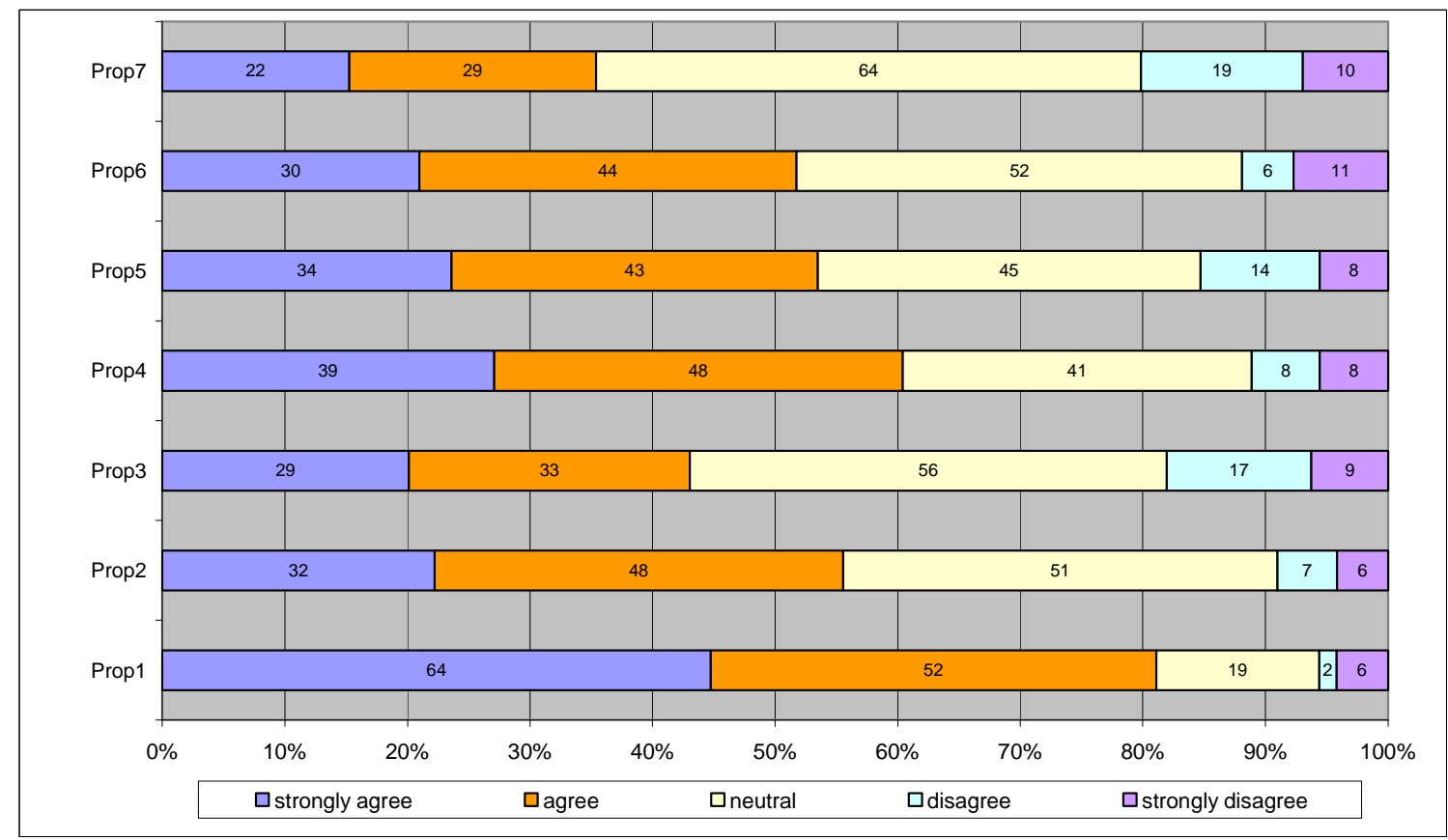

Table 7 ranks the propositions according to the evaluations by the respondents, by means of the following measure:

Score $($ prop $)=\frac{2 *(\# \text { stronglyagree })+\# \text { agree }}{2 *(\# \text { strongly disagree })+\# \text { disagree }}$

Table 7 shows that the respondents agree the most on proposition 1, and the least on proposition 7. In the next subsections, propositions 1, 2 and 7 are discussed in detail for the different categories of LSPs.

Table 7

Ranking of opportunities of cooperation

\begin{tabular}{lcc}
\hline Opportunities of cooperation & $\begin{array}{c}\text { Prop. } \\
\text { no. }\end{array}$ & Score \\
\hline $\begin{array}{l}\text { Horizontal cooperation increases the company's productivity for core activities, } \\
\text { e.g.: decrease in empty hauling, better usage of storage facilities etc. }\end{array}$ & 1 & 12.9 \\
$\begin{array}{l}\text { Horizontal cooperation reduces the costs of non-core activities, e.g.: organizing } \\
\text { safety trainings, joint fuel facilities etc. }\end{array}$ & 2 & 5.9 \\
$\begin{array}{l}\text { LSPs can specialize, while at the same time broadening their services. } \\
\text { Tendering on larger contracts with large shippers becomes possible. }\end{array}$ & 4 & 5.3 \\
LSPs can offer better quality of service at lower costs. & 5 & 3.7 \\
Partnerships reduce purchasing costs, e.g.: vehicles, onboard computers, fuel etc. & 3 & 3.7 \\
Forming partnerships helps to protect market share. & 7 & 1.6 \\
\hline
\end{tabular}




\subsection{Proposition 1: Cooperation increases the company's productivity for core activities}

The proposition that horizontal cooperation increases the productivity of core activities is strongly supported (see Figure 3). More than $80 \%$ of the respondents support this claim. In the open questions in the survey and in the in-depth interviews, reducing empty haulage, increasing the load factors (vehicle capacity utilization) and improving the back office organization were often reported to be main drivers for productivity improvements.

Figure 3

Horizontal cooperation increases the productivity for core activities

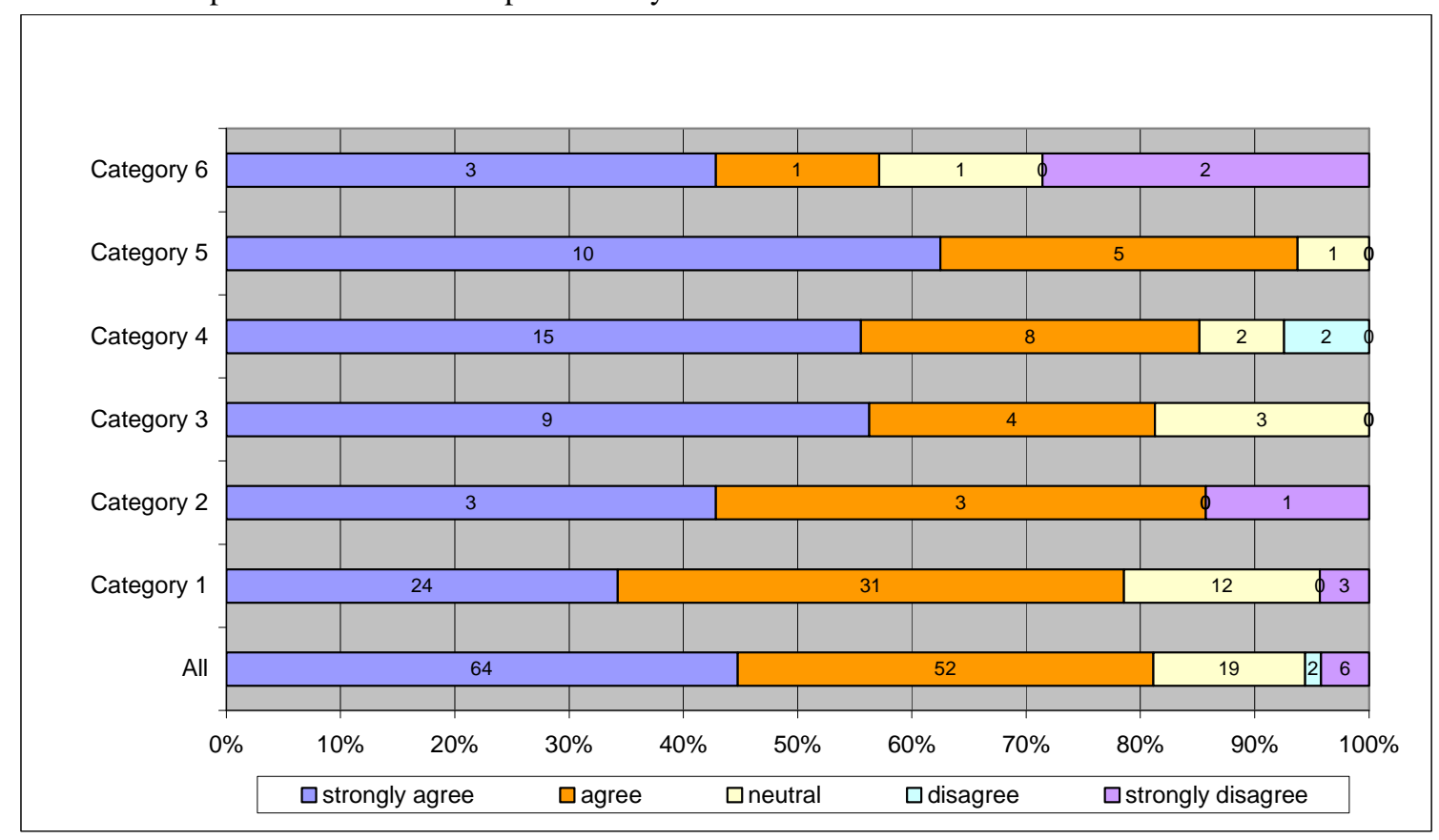

Although Figure 3 indicates that all categories of LSPs agree on this proposition, the express carriers (category 6, only 7 observations) seem to be the most reluctant. Possibly this is because of the high time pressure within the industry, prohibiting an intensive consolidation of partial loads.

Category 5 (LSPs offering Value Added Services as their core activity, see Table 6) supports Proposition 1 the most: none of the 16 companies in this category disagrees. Their positive attitude could be motivated by the often wide variety of services that these LSPs offer. As a result, horizontal collaboration offers a potential for significant scale and learning effects.

\subsection{Proposition 2: Horizontal cooperation reduces the costs of non-core activities}

LSPs for whom transportation is the most important activity (categories 1,2 and 6) are to a large extent neutral concerning the proposition that horizontal cooperation can reduce the costs of non-core activities (see Figure 4). In contrast, LSPs offering Value Added 
Services (categories 4 and 5) and the freight forwarders (category 3) agree with the proposition quite strongly. Because of the wider range of services offered, these LSPs are more frequently involved in non-core activities. By cooperating, the costs of the non-core activities can be significantly reduced, since cooperation allows partners to specialize.

Figure 4

Horizontal cooperation reduces the costs of non-core activities

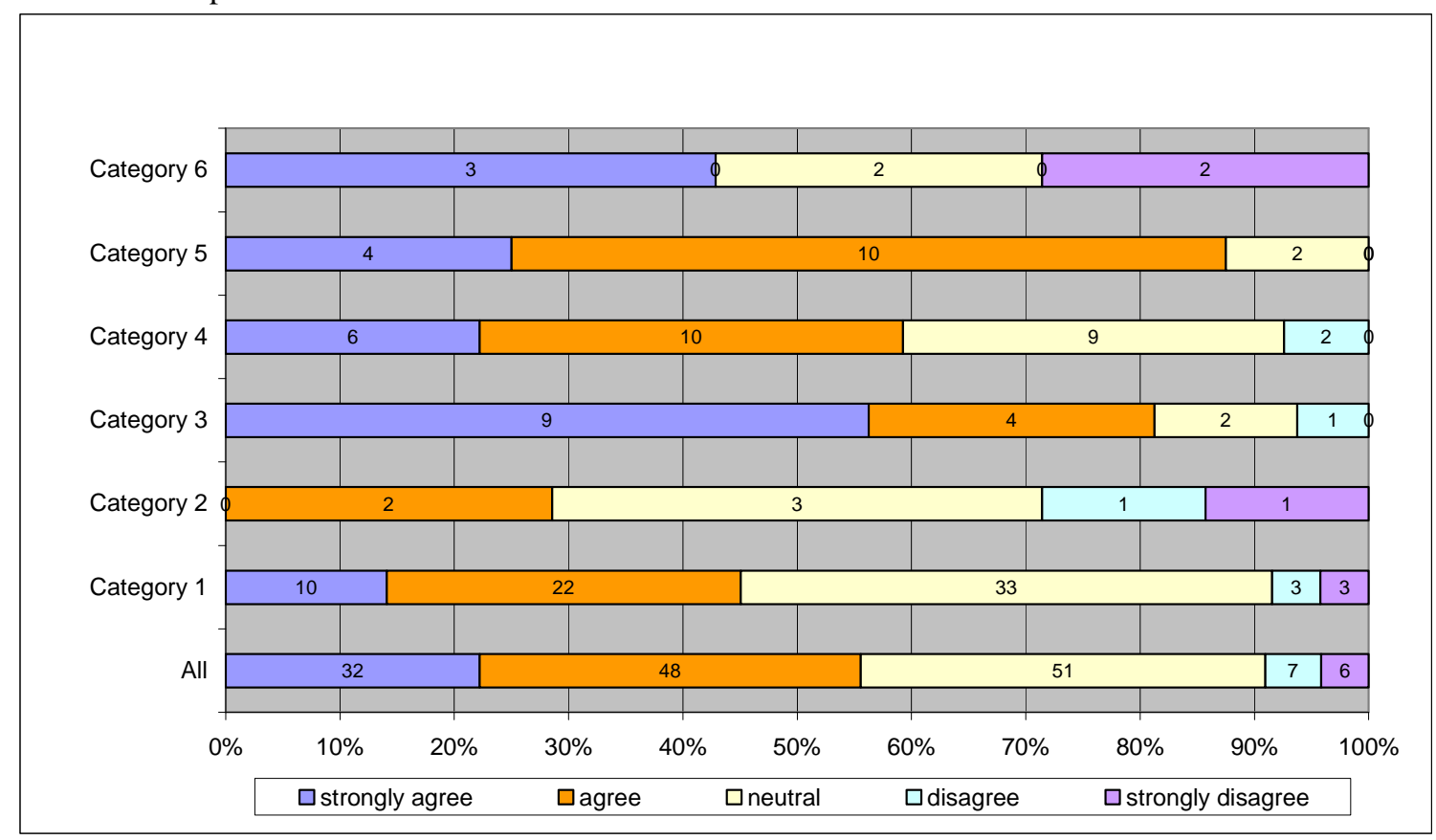

\subsection{Proposition 7: Forming partnerships helps to protect market share}

Figure 5 shows the evaluation of the proposition that received the least support from the respondents. For all categories of LSPs, a large part of the respondents is neutral about proposition 7, which makes it hard to draw clear-cut conclusions. Recent research by Becker et al. (2004) on shippers' attitude towards cooperation between LSPs revealed that shippers are not interested in an increased cooperation amongst LSPs. Most frequently shippers prefer a larger negotiating power over the possibility of 'one stop shopping' in a group of collaborating LSPs. The evaluation of propositions 1 and 7 indicates that LSPs consider partnerships mainly as a means to increase the efficiency of logistic services to meet existing shipper requirements. 
Figure 5

Horizontal cooperation helps to protect market share

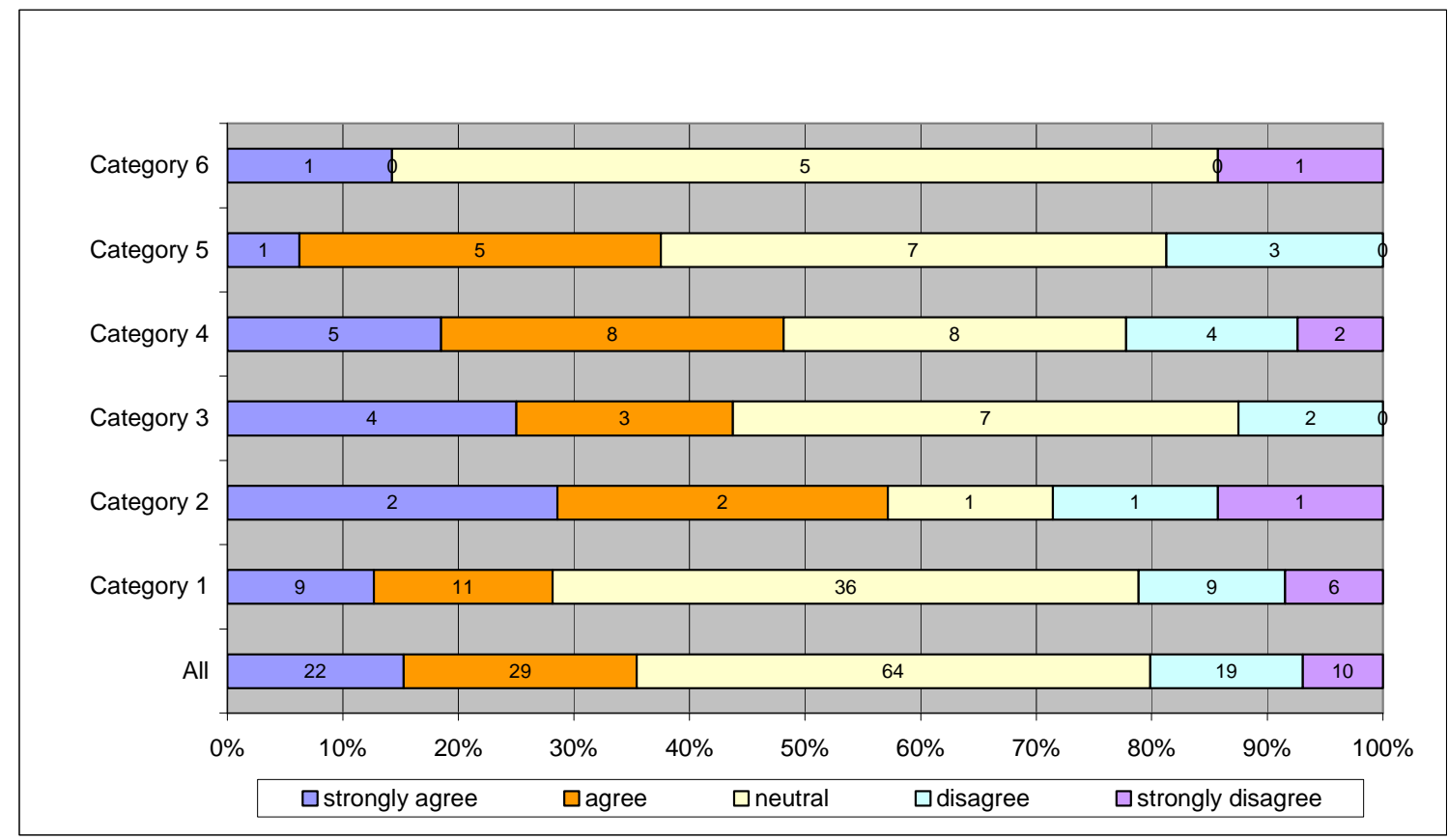

\section{Impediments for horizontal cooperation}

This section contains the evaluation of the propositions on the impediments for cooperation listed in Table 2 in Section 2. First, the complete set of nine propositions will be discussed for the full set of respondents. Second, the three most striking results will be discussed in detail for each of the six categories of LSPs.

Except for proposition 8, each proposition in Figure 6 is supported by the majority of the respondents. 
Figure 6

Impediments for cooperation

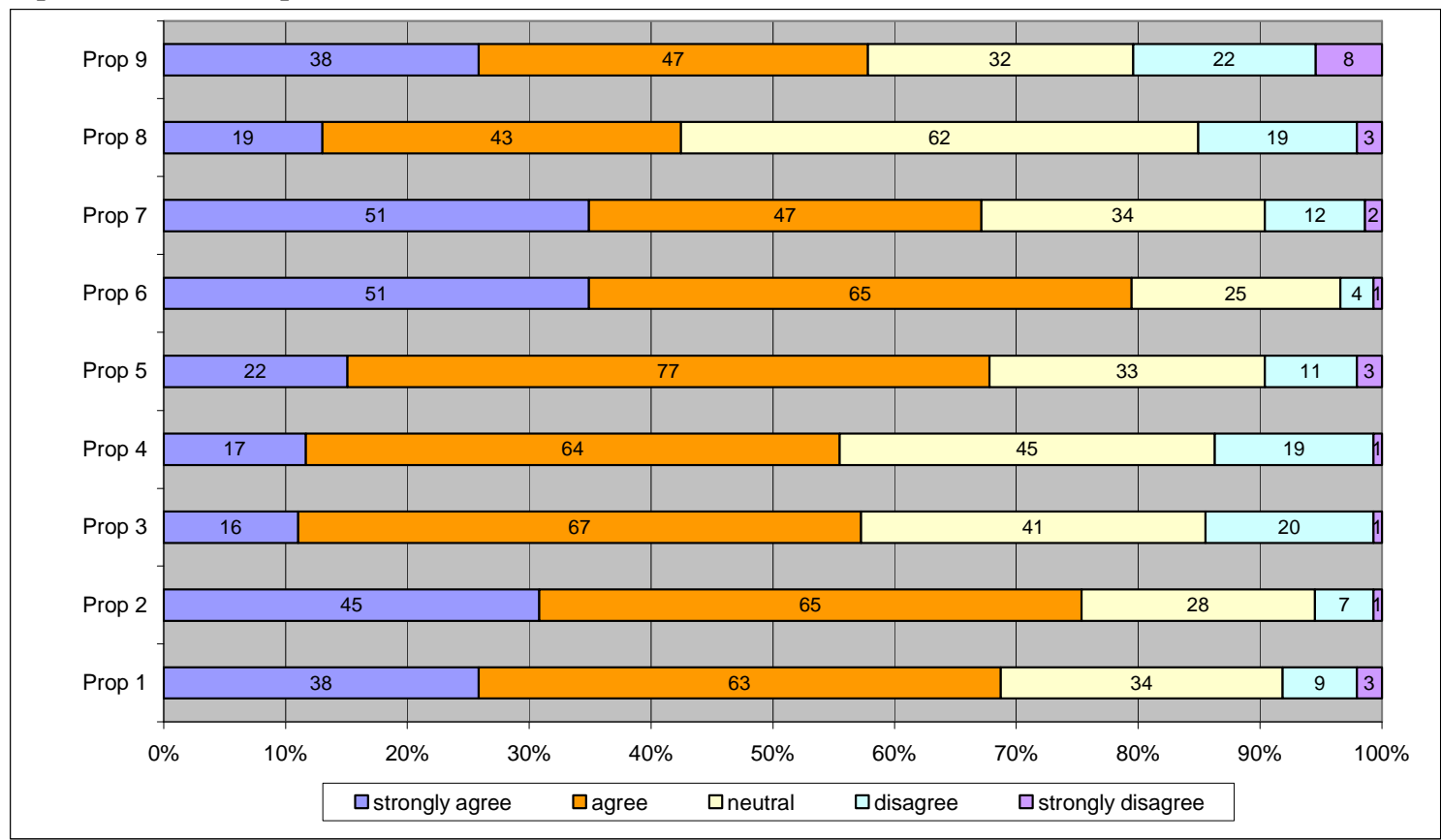

Table 8 ranks the propositions according to formula (1), revealing that propositions 6 and 2 are supported very strongly by the respondents.

Because the evaluation by an LSP of possible impediments for cooperation may depend on whether or not it is already cooperating, the set of respondents is split into two subsets. A respondent is labeled a 'cooperator' if it has indicated to be currently cooperating on either core or non-core activities. Respondents that do not cooperate in any way are labeled as 'non-cooperators'. In Figure 10 in the Appendix, the results from Figure 6 are broken down into cooperating and non-cooperating LSPs.

Based on the data in Figure 10, we conjecture that there are no significant differences between the evaluations of the impediments for cooperation by the two groups. Stated differently, the experiences that cooperators have with the impediments are in accordance to the expectations of the impediments by the non-cooperators. We tested this conjecture using contingency table analysis. The last column of Table 8 shows the two-tailed $\mathrm{P}$ values, resulting from a Fisher exact test for the nine propositions about impediments for cooperation considered in this paper. We conclude that for none of the propositions, the difference in the evaluations by cooperators and non-cooperators are statistically significant (Fisher exact test 0.151 or larger). 


\section{Table 8}

Ranking impediments for cooperation

\begin{tabular}{lccc}
\hline Propositions about impediments for cooperation & Score & Prop. No. & $\begin{array}{c}\text { Fisher } \\
\text { exact }\end{array}$ \\
\hline $\begin{array}{l}\text { A fair allocation of the benefits is essential for a successful } \\
\text { cooperation. }\end{array}$ & 27.8 & 6 & 0.541 \\
$\begin{array}{l}\text { It is hard to find a reliable party that can coordinate the cooperation } \\
\text { in such a way that all participants are satisfied. }\end{array}$ & 17.2 & 2 & 0.624 \\
$\begin{array}{l}\text { Smaller companies in the partnership may lose clients or get pushed } \\
\text { out of the market completely. }\end{array}$ & 9.3 & 7 & 0.894 \\
$\begin{array}{l}\text { It is hard to find commensurable LSPs with whom it is possible to } \\
\text { cooperate for (non-) core activities. }\end{array}$ & 9.3 & 1 & 0.151 \\
$\begin{array}{l}\text { It is hard to ensure a fair allocation of the shared workload in } \\
\text { advance. }\end{array}$ & 7.1 & 5 & 0.811 \\
$\begin{array}{l}\text { It is hard to determine the benefits or operational savings due to } \\
\text { horizontal cooperation beforehand. }\end{array}$ & 4.7 & 4 & 0.413 \\
$\begin{array}{l}\text { When an LSP cooperates with commensurable companies, it } \\
\text { becomes harder to distinguish itself. }\end{array}$ & 4.5 & 3 & 0.566 \\
$\begin{array}{l}\text { Benefits cannot be shared in a fair way, the larger players will } \\
\text { always benefit most. }\end{array}$ & 3.2 & 9 & 0.427 \\
$\begin{array}{l}\text { Cooperation is greatly hampered by the required indispensable ICT- } \\
\text { investments. }\end{array}$ & 3.2 & 8 & 0.997 \\
\hline
\end{tabular}

Because of the high variability in the evaluation of propositions 6,2 and 7 by the various categories of LSPs, these propositions will now be analyzed in detail.

\subsection{Proposition 6: A fair allocation of the benefits is essential for a successful cooperation}

The major impediment for cooperation consists of distributing the benefits generated by the partnership. Each category of LSP strongly agrees with the proposition that it is hard to construct a fair allocation mechanism. As can be calculated from Figure 7, the share of respondents who agree with the proposition ranges from $69 \%$ (category 5) to $89 \%$ (category 4). 
Figure 7

Proposition: A fair allocation of the benefits is essential for a successful cooperation.

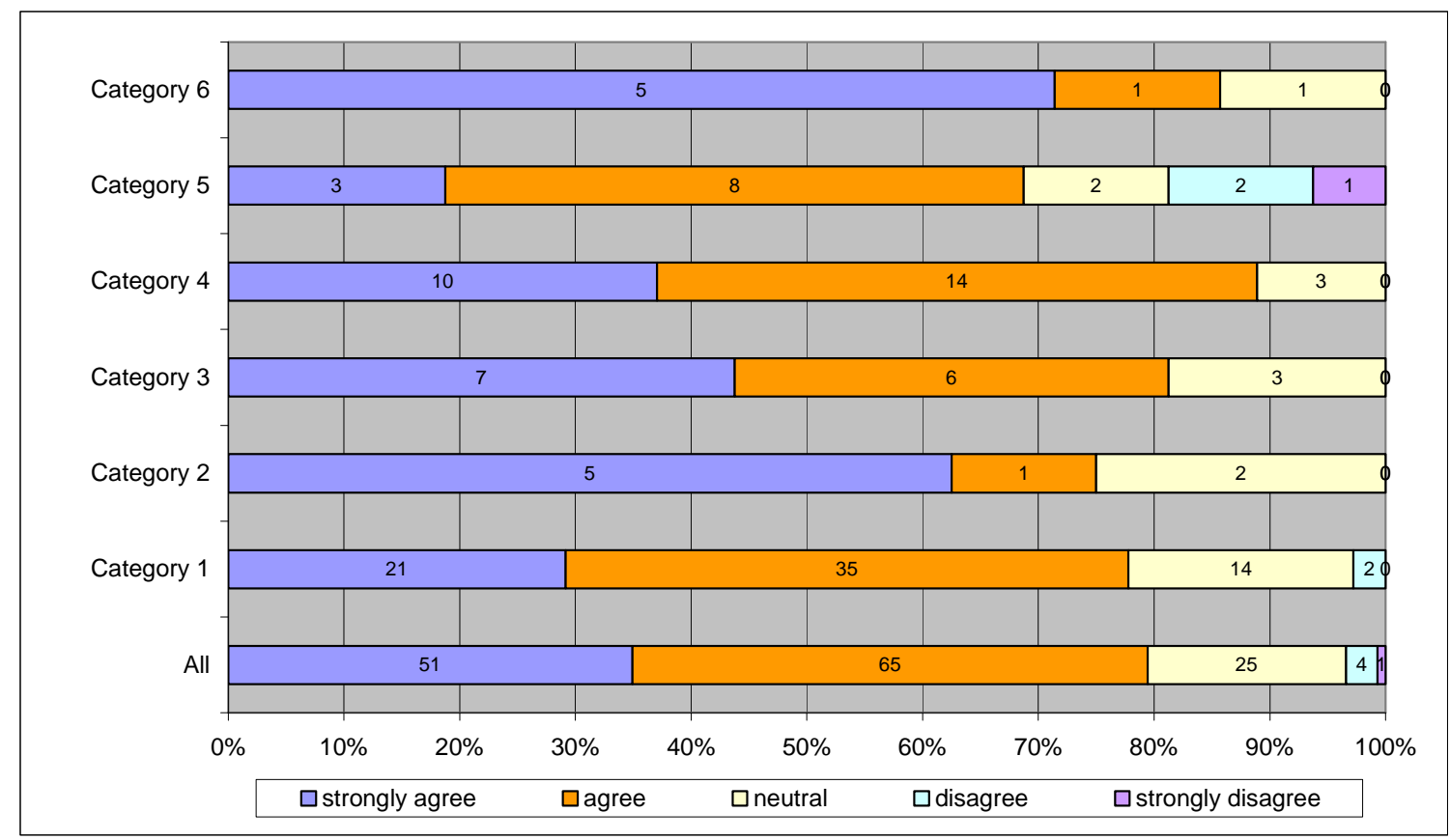

In-depth interviews revealed that some pragmatism could reduce or circumvent the issue of distributing the benefits. In the case of freight exchange between LSPs for example, the company that submits a transportation order in the pool of the cooperation could charge a commission to compensate for its efforts in acquiring the order. If none of the other partners in the cooperation decides to accept the order, the company that submitted the order in the pool has to complete the order itself. In this way, difficult issues on the determination and distribution of the savings can be avoided.

\subsection{Proposition 2: It is hard to find a reliable party that can coordinate the cooperation in such a way that all participants are satisfied}

All categories of LSPs strongly agree with the proposition that it is hard to find a reliable partner to coordinate the cooperation in such a way that all partners are satisfied (see Figure 8). The small and medium-sized express carriers (category 6) in the sample even support this claim unanimously, possibly because of the widespread mistrust in the express transportation sector. Although most of the express carriers realize that their productivity can be increased by cooperating with their competitors, answers to open questions point out that potential partners are suspected of having hidden motives to enter a partnership such as taking in market share and gaining insight in a competitor's business structure. 
Figure 8

Proposition: It is hard to find a reliable party that can coordinate the cooperation in such a way that all participants are satisfied.

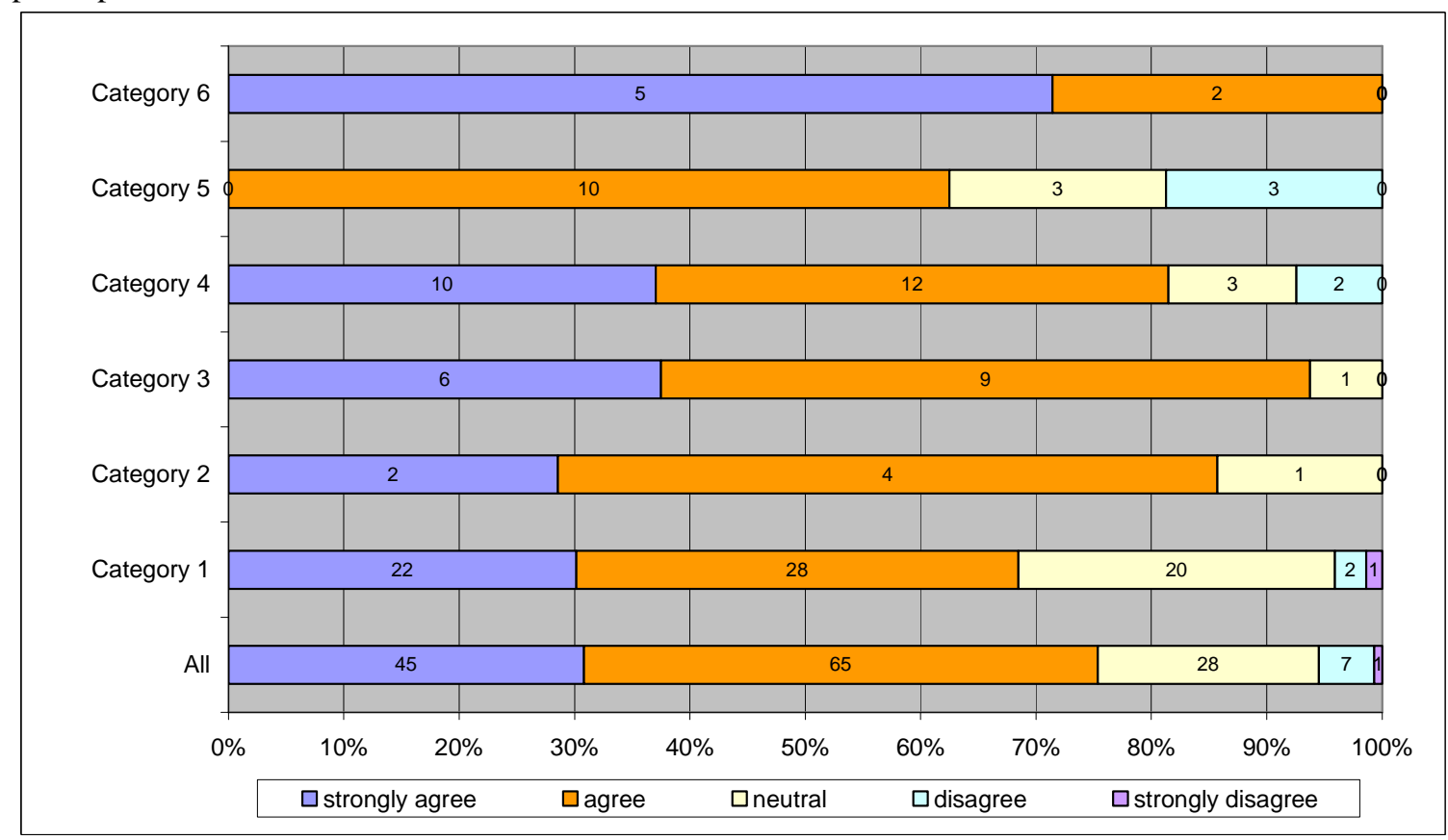

In the survey, respondents were asked whether it would be better to have an independent third party coordinating the partnership. Table 9 shows that the majority of the respondents do not consider independent parties the most adequate candidates to lead and coordinate a cooperation. This suggests that there is little demand for Fourth Party Logistic parties or consultants to start up or coordinate horizontal partnerships.

Table 9

Do you think it to be preferable that a third independent party coordinates the partnership?

\begin{tabular}{|l|l|l|}
\hline Frequency & "YES" & "NO" \\
\hline $\begin{array}{l}\text { Additional } \\
\text { remarks }\end{array}$ & $\begin{array}{l}\text { Provided that the coordinator carries } \\
\text { responsibility. }\end{array}$ & $\begin{array}{l}\text { It is preferable to remain in complete } \\
\text { control. }\end{array}$ \\
& $\begin{array}{l}\text { A third party can be useful in bringing } \\
\text { parties together and exploring the } \\
\text { possibilities of a partnership. }\end{array}$ & $\begin{array}{l}\text { One of the participants should coordinate } \\
\text { the partnership. }\end{array}$ \\
\hline
\end{tabular}

\subsection{Proposition 7: Smaller companies in the partnership may lose clients or get pushed out of the market completely}

$35 \%$ of the respondents point out that they strongly agree with the proposition that in the long run smaller partners within the partnership run the risk of losing customers to larger partners (see Figure 9). Yet, those respondents that generate most of their revenues by offering Value Added Services (category 5) are a striking exception to the rule. These companies feel that they have a stronger market position than 2PL providers, i.e. those LSPs who typically focus exclusively on transportation services. Because of the higher 
degree of specialization of the category 5 LSPs, their services become less interchangeable with those of colleague LSPs. Therefore they seem to experience a lower risk of losing customers and they hesitate less to collaborate with competitors.

Figure 9

Proposition: Smaller companies in the partnership may lose clients or get pushed out of the market completely.

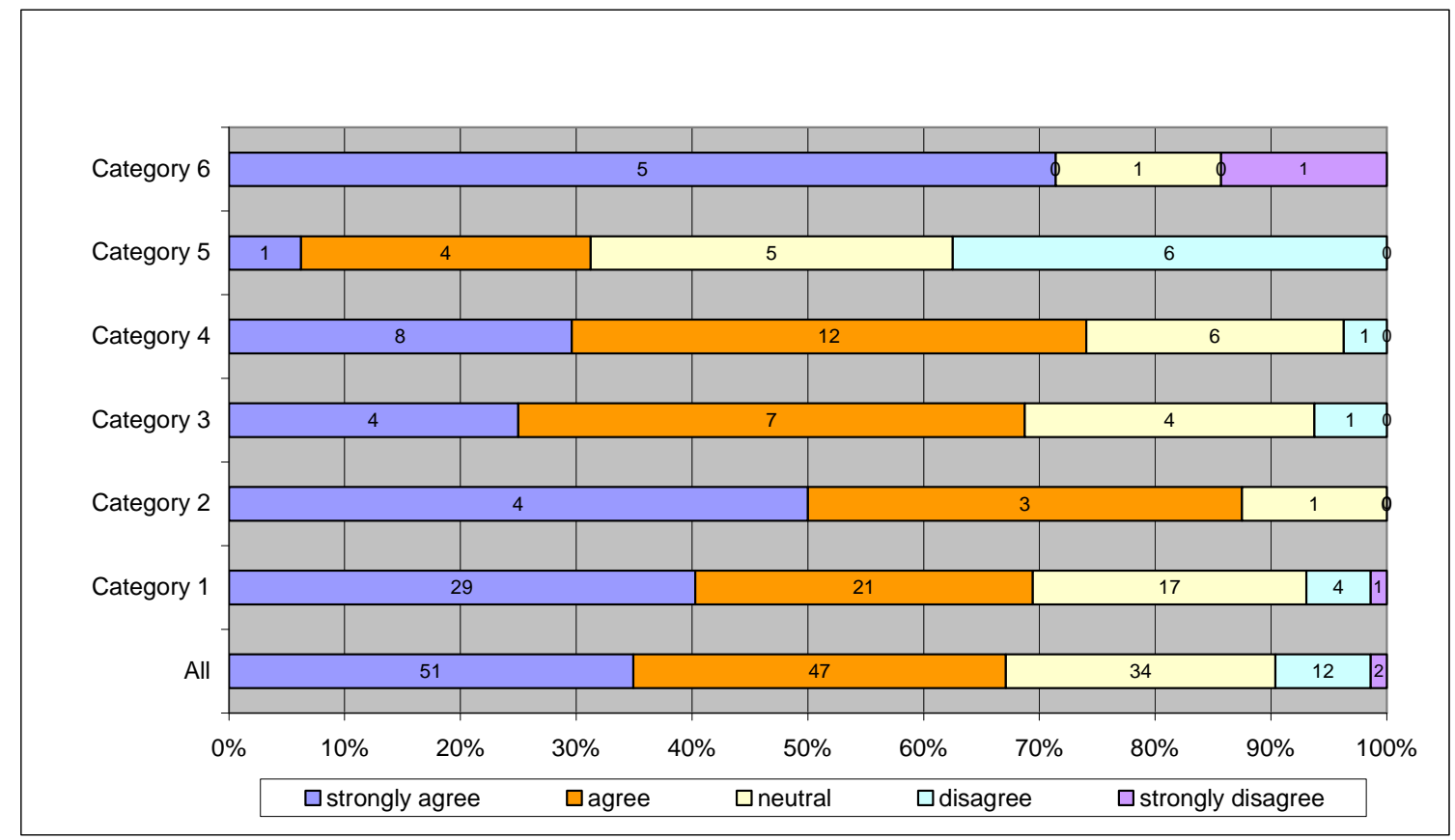

\subsection{Other impediments for horizontal cooperation}

In the questionnaire respondents were asked to report on additional impediments for structural, long-term cooperation encountered in practice. The answers are summarized in Table 10, together with their frequency. The fact that 14 respondents consider the small size of their company to be an impediment for cooperation is striking. These small-sized LSPs ( 1 or 2 full time equivalent employees) either lack the business connections to set up a partnership or have a small number of customers that fills their capacity entirely. 
Table 10

Additional impediments for cooperation

\begin{tabular}{lr} 
Explanation & Frequency \\
\hline Our company is too small. & 14 \\
Incidental cooperation is OK, but structural cooperation is not desirable because of & 6 \\
competition considerations. & 5 \\
Agreements are not complied with in a cooperation. & 4 \\
Competition prohibits cooperation. & 4 \\
We are interested in joining a partnership, but the Flemish logistic sector lacks the & 4 \\
broad vision that is necessary to start such initiatives. & 2 \\
Our company offers services that are too specialized. & 2 \\
We do not yet cooperate horizontally, but we are looking for partners. & 2 \\
Cooperation is impossible in the Flemish logistic sector. & 1 \\
We have not thought about it yet. & 1 \\
The government does not sufficiently support cooperation. & 1 \\
There is not enough high-level deliberation in the logistic sector. & 1 \\
The company is large enough to deal with all requirements of the customers. & \\
Because of heavy time pressure of the day-to-day operations, we do not have the & 1 \\
possibility to implement structural changes in the business processes. & \\
Strict (time) requirements of the customers make cooperation impossible. &
\end{tabular}

\section{Summary, discussion and tracks for future research}

In order to provide an overview of the potential benefits of horizontal collaboration between LSPs and the main impediments for implementation, 1.537 LSPs were contacted in Flanders, Belgium. Together with The Netherlands, Flanders is the center of gravity of logistics services in Europe, hosting the vast majority of European Distribution Centers.

The main finding is that in general LSPs believe in the potential of horizontal cooperation to increase their profitability or to improve the quality of their services. Although cooperation on core activities involves the exchange of customer information, cooperation on those activities is yet considered to be more interesting than cooperation on non-core activities because of the higher potential of cost savings. The impediments for cooperation that are perceived or expected by the non-cooperating LSPs prove to be experienced by the cooperating LSPs.

Removing the actual impediments for cooperation is a first major avenue for further research. The respondents consider the estimation of potential cost savings and the measurement and distribution of actual cost savings as important impediments for cooperation. To the best of our knowledge, the literature on distributing cost savings is limited. There is, however, a considerable amount of literature on allocating joint costs among multiple business entities, e.g. of a warehouse shared by a group of LSPs. The problem of allocating the costs for such a shared resource has been approached by using data envelopment analysis (e.g. Cook and Kress, 1999; Beasley, 2003; Jahanshahloo, 2004) and cooperative game theory (e.g. Sakawa et al., 2001). Apart from the fixed costs of a partnership between LSPs, also the variable costs of the daily operations must be allocated to the partners. If, for example, customers of several LSP partners are serviced 
in the same route, the obtained synergetic benefits must be allocated to these LSPs. This problem shows many similarities with well-known game-theoretic problems, such as the traveling salesman game (e.g. Engevall et al., 1998), the (extended) tree game (e.g. Granot et al., 2002), transportation games (e.g. Sanchez-Soriano et al., 2001), cost allocation in the Chinese postman problem (e.g. Hamers et al., 1999), and cost allocation in the vehicle routing problem (e.g. Engevall et al., 2004). Despite of the considerable amount of research that has been conducted on the subject of cost allocation, the practical use of the models developed in these papers is limited. The allocation rules that are developed are often complicated and only capable of solving small problem instances. Both the survey and the in-depth interviews revealed that LSPs need methods that are capable of measuring and distributing the savings resulting from real-life cooperation problems in a transparent way. Developing 'second-best' practical methods for estimating, measuring and distributing the benefits of cooperation, possibly based on 'first-best' methods from game theory, is a first major research avenue.

Although the questionnaire did not contain any questions on the time path of the savings resulting from cooperation, it could be observed that many of the reported partnerships aim at generating cost savings as quickly as possible. Because of the low profit margins within the logistics industry, LSPs are often limited to embarking on collaboration agreements that generate cost savings right from the start although more challenging collaboration agreements could yield a larger return in the long run in spite of a small or negative initial return. Studying the time path of cost savings for various forms of logistic collaboration offers a second important research direction. 


\section{Appendix}

This appendix provides the evaluations of the propositions about the impediments for cooperation by the cooperators and the non-cooperators, respectively. Based on Figure 10 , we conjectured that there are no significant differences between the evaluations of the impediments by cooperators and non-cooperators (see Section 5).

Figure 10

Impediments for cooperation as perceived by cooperators vs. non-cooperators

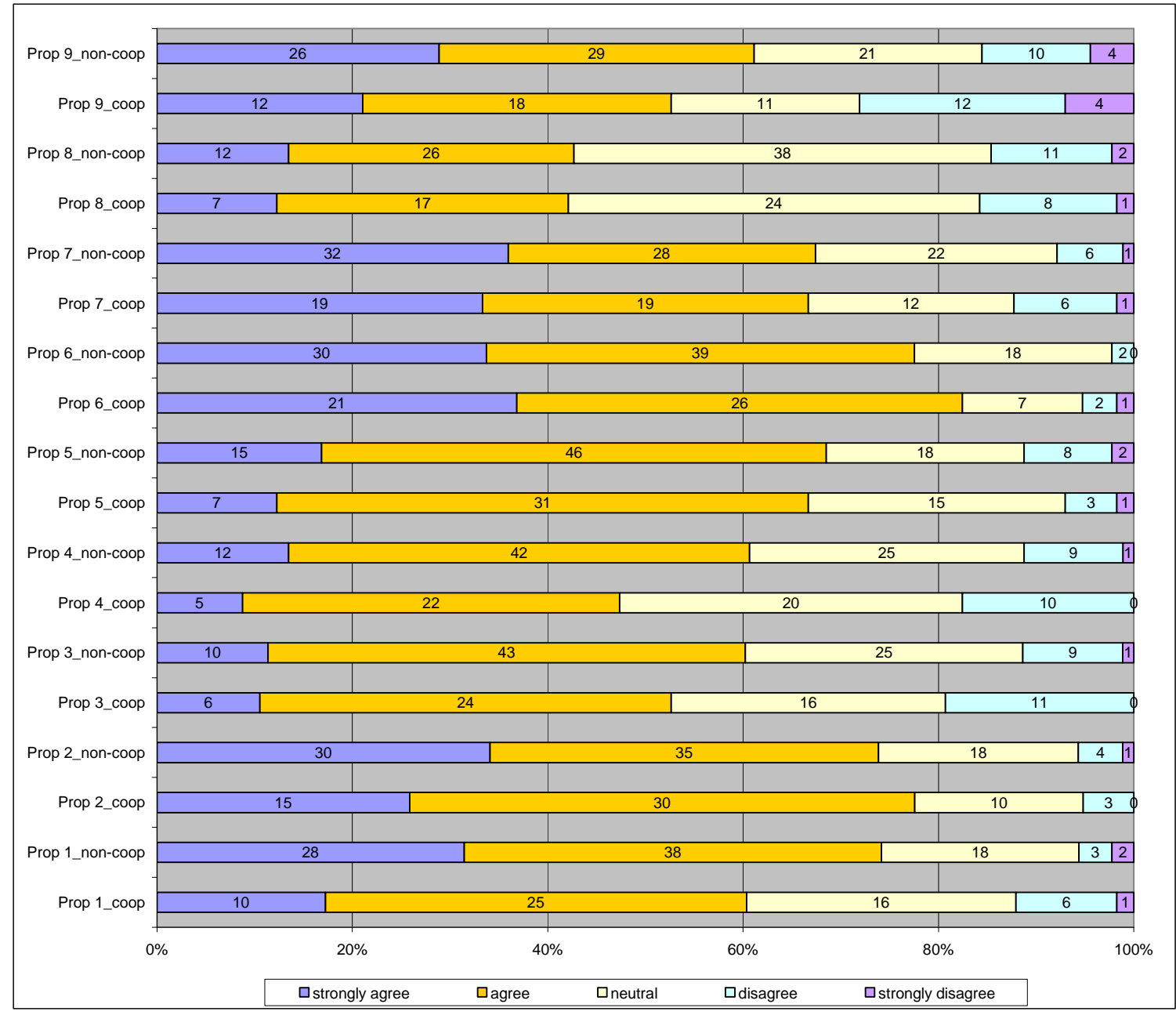




\section{References}

1. Bahrami K. (2003) Horizontale Transportlogistik-Kooperationen: Synergiepotenzial für Hersteller kurzlebiger Konsumgüter [German], Deutscher Universitäts-Verlag, Wiesbaden Köln

2. Beasley $\mathbf{J}$ (2003) Allocating fixed costs and resources via data envelopment analysis. European Journal of Operational Research 147: Special issue on O.R. Applications: 198-216

3. Becker J, M Cools, F Cruijssen, W Dullaert, B Vannieuwenhuyse, T Verduijn. (2004) Samenwerking in logistieke dienstverlening: Visie van Vlaamse verladers en dienstverleners [Dutch], in Ruijgrok en Rodenburg (eds.), Bijdragen Vervoerslogistieke Werkdagen

4. BelFirst (2004) FInancial Reports and Statistics on Belgian and Luxembourg Companies. http://www.bib.ulb.ac.be/BSH/eco/cd-rom/belfirst.htm Last visited: 04/08/2004

5. Bolumole Y. (2003) Evaluating the Supply Chain Role of Logistics Service Providers. International Journal of Logistics Management 14 (2): 93-107

6. Bowman R. (1995) A high wire act. Distribution 94: 36-39. Bradley P (1994) Transportation report: what really matters. Purchasing 117 (1): 66-71

7. Cook W, M Kress (1999) Characterizing an equitable allocation of shared costs: A DEA approach. European Journal of Operational Research 119: 652-661

8. Cruijssen F, M Salomon (2004) Empirical study: Order sharing between transportation companies may result in cost reductions between 5 to 15 percent. CentER Discussion Paper 2004-80

9. Davis D. (1995) Third parties deliver. Manufacturing systems 13: 66-68

10. Dullaert W, M Cools, F Cruijssen, H Fleuren, F Merckx. (2004) Analyse Samenwerkingsopportuniteiten [In Dutch] Report for Flanders Instute for Logistics (VIL) as part of the strategic workgroup Collaborative Networks.

11. Dyer J, H Singh (1998) The relational view: Cooperative strategy and sources of interorganizational competitive advantage. The Academy of Management Review 23 (4): 660-679

12. Engevall S, M Göthe-Lundgren, $P$ Värbrand (1998) The traveling salesman game: An application of cost allocation in a gas and oil company. Annals of Operations Research 82: $453-471$

13. Engevall S, M Göthe-Lundgren, P Värbrand (2004) The Heterogeneous Vehicle-Routing Game. Transportation Science 38 (1): 71-85 
14. Erdmann M. (1999) Konsolidierungspotentiale von Speditionskooperationen: eine simulationsgestützte Analyse [German], Deutscher Universitäts-Verlag, Wiesbaden Köln

15. Esper T, L Williams (2003) The value of Collaborative Transportation Management (CTM): Its relationship to CPFR and Information technology. Transportation Journal 42 (4): 55-65

16. Fan T, Vigeant-Langlois L, Geissler C, Bosler B, Wilmking J (2001) Evolution of global airline strategic alliance and consolidation in the twenty-first century. Journal of Air Transport Management 7 (6): 349-360

17. FMEA (Flemish Ministery of Economic Affairs) website (2003) http://www.mineco.fgov.be/enterprises/crossroads_bank/xls/NACE-BEL_NL.xls Last visited: 04/08/2004

18. Gentry J (1993) Strategic alliances in purchasing: transportation is the vital link. International Journal of Purchasing and Materials Management 29(3): 11-17

19. Gibson B, S Rutner, S Keller (2002) Shipper-carrier partnership issues, ranking and satisfaction. International Journal of Physical Distribution \& Logistics Management 32 (8): 669-681

20. Granot D, J Kuipers, S Chopra (2002) Cost allocation for a tree network with heterogeneous customers. Mathematics of Operations Research 27 (4): 647-661

21. Hamers H, P Borm, R van de Leensel, S Tijs (1999) Cost allocation in the Chinese postman problem. European Journal of Operational Research 118: Special Issue Theory and Methodology: 153-163

22. Harrington L (1996) Logisitcs assets: Should you own or manage? Transportation \& Distribution 37: 51-54

23. Industrie Vlaanderen (2004). www.industrievlaanderen.be Last visited: 04/08/2004.

24. Jahanshahloo G, F Hosseinzadeh Lotfi, N Shoja and M Sanei (2004) An alternative approach for equitable allocation of shared costs by using DEA. Applied Mathematics and Computation 153 (1): 267-274

25. Land 'O Lakes (2003) www.cioinsight.com/article2/0,1397,1072267,00.asp Last visited: $04 / 08 / 2004$

26. Leahy S, P Murphy, R Poist (1995) Determinants of successful logistical relationships: A third party provider perspective. Transportation Journal 35: 5-13

27. Oum T, J-H Park, K Kim, C Yu (2002) The effect of horizontal alliances on firm productivity and profitability: evidence from the global airline industry. Journal of Business Research 854: 1-10

28. Ritter T, H Gemünden (2003) Interorganizational relationships and networks: An overview. Journal of Business Research 56: 691-697 
29. Sakawa M, I Nishizaki, Y Uemura (2001) Fuzzy programming and profit and cost allocation for a production and transportation problem. European Journal of Operational Research 131: 1-15

30. Sanchez-Soriano J, M Lopez, I. Garcia-Jurado (2001) On the core of transportation games. Mathematical Social Sciences 41: 215-225

31. Shepperd E and D Seidman (2001) Ocean shipping alliances: the wave of the future? International Journal of Maritime Economics 3 (4): 351-367

32. Simchi-Levi D, P Kaminsky, E Simchi-Levi (1999) Designing and Managing the Supply Chain: Concepts, Strategies, and Cases, McGraw-Hill, 1999 ISBN: 0-07-235756-8

33. Smith K, S Carroll, S Ashford (1995) Intra- and Interorganizational Cooperation: Toward a Research agenda. Academy of Management Journal 38 (1): 7-23

34. Tate K (1996) The elements of a successful partnership. International Journal of Physical Distribution \& Logistics Management 26(3): 7-13

35. Tyan J, F Wang, T Du (2003) An evaluation of freight consolidation policies in global third party logistics Omega 31(1): 55-62

36. Vos B, M Iding, M Rustenburg, C Ruijgrok (2003). Synergievoordelen in Logistieke NETwerken (SYLONET) - deel 1 [Dutch], TNO Inro rapport 033N08832001

37. Wouters M, K Kokke, J Theeuwes, K van Donselaar (1999) Identification of critical operational performance measures - a research note on a benchmarking study in the transportation and distribution sector. Management Accounting Research 10: 439-452 